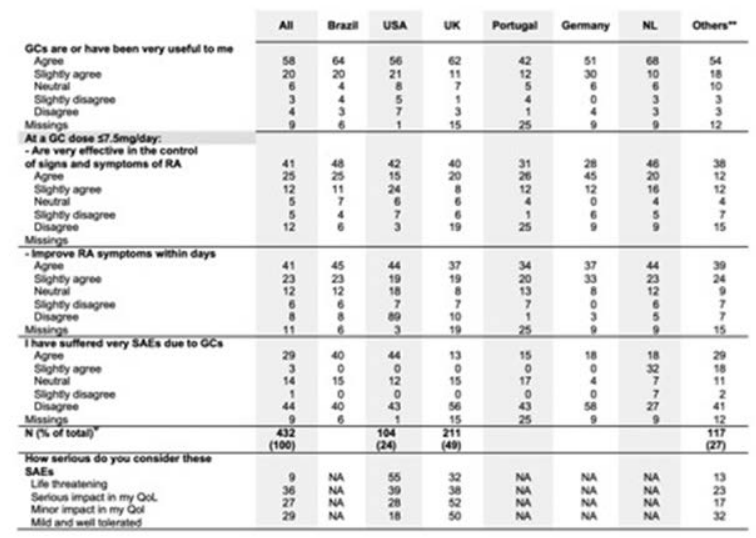

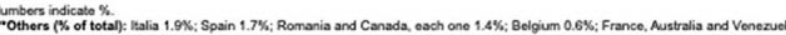

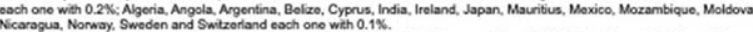
"The Portugueso. Germany and Deutschland version as woll as the Engiah survey through MedGuard.org. didn't have this question due

Disclosure of Interests: Tânia Santiago: None declared, Marieke Voshaar Grant/research support from: part of phd research, Speakers bureau: conducting a workshop (Pfizer), Maarten de Wit Grant/research support from: Dr. de Wit reports personal fees from Ely Lilly, 2019, personal fees from Celgene, 2019, personal fees from Pfizer, 2019, personal fees from Janssen-Cilag, 2017, outside the submitted work., Consultant of: Dr. de Wit reports personal fees from Ely Lilly, 2019, personal fees from Celgene, 2019, personal fees from Pfizer, 2019, personal fees from Janssen-Cilag, 2017, outside the submitted work., Speakers bureau: Dr. de Wit reports personal fees from Ely Lilly, 2019, personal fees from Celgene, 2019, personal fees from Pfizer, 2019, personal fees from Janssen-Cilag, 2017, outside the submitted work., Pedro Carvalho: None declared, Maarten Boers: None declared, Maurizio Cutolo Grant/research support from: Bristol-Myers Squibb, Actelion, Celgene, Consultant of: Bristol-Myers Squibb, Speakers bureau: Sigma-Alpha, Frank Buttgereit Grant/research support from: Amgen, BMS, Celgene, Generic Assays, GSK, Hexal, Horizon, Lilly, medac, Mundipharma, Novartis, Pfizer, Roche, and Sanofi., José Antonio P. da Silva Grant/ research support from: Pfizer, Abbvie, Consultant of: Pfizer, AbbVie, Roche, Lilly, Novartis

DOI: 10.1136/annrheumdis-2020-eular.3277

\section{AB1336-HPR NON-PHARMACOLOGIC TOPICS RELEVANT FOR CLINICAL RESEARCH IN RHEUMATIC DISEASES: THE PATIENT PERSPECTIVE}

F. Ingegnoli ${ }^{1,2}$, T. Schioppo $^{1,2}$, T. Ubiali $^{1}$, S. Ostuzzi ${ }^{3}$, M. Buoli ${ }^{2,4}$, V. Bollati $^{2,5}$, R. Caporali ${ }^{1,2},{ }^{1}$ G Pini Hospital, Clinical Rheumatology Unit, Milan, Italy; ${ }^{2}$ Università degli Studi di Milano, Milan, Italy: ${ }^{3}$ A LOMAR Lombard Association for Rheumatic Diseases, Milan, Italy; ${ }^{4}$ IRCCS Ca'Granda Policlinico, Milan, Italy; ${ }^{5}$ EPIGET Lab, Milan, Italy

Background: The research approach on Rheumatic diseases (RDs) is challenging and patient involvement as partners in medical research is an emerging force to obtain relevant information and to add unique skills, values and experiences to research. Despite growing interest in non-pharmacologic aspects of clinical research in RDs, the patients' perspective is currently poorly explored.

Objectives: To identify and rank the priorities for clinical research according to patients' perspective.

Methods: A structured face-to-face meeting between physicians and a patient representative was convened to list the non-pharmacologic topics relevant to RD patients. A cross-sectional no-profit on-line anonymous survey was devised to evaluate opinions of RD patients. They were asked to rate the following topics: food/nutrition, air pollution, smoking, work activity, social participation, physical activity, emotional well-being/stress, alternative medicine, and patient-physician relationship. Moreover, patients were asked to explain for which reason a topic was considered important (disease prevention, halting disease progression, symptoms control and disease cure). The survey was disseminated by ALOMAR (Lombard Association for Rheumatic Diseases) between June and October 2019. Results: 200 rheumatic patients completed the survey: 130 inflammatory arthritis, 50 connective tissue diseases/vasculitis, and 20 among osteoarthritis, gout, condrocalcinosis, polymyalgia and primary fibromyalgia. Respondents were 178 female with median age of 50 years and median disease duration of 7 years. Among the nine topics identified, the one most rated by patients was the doctor-patient relationship; $188(94 \%)$ of respondents considered this topic very or extremely important (see table below). In descending order, patients rated very or extremely important: psychological well-being/stress 185 (92.5\%), physical activity $155(77.5 \%)$, nutrition, eating habits and alcohol 150 (75\%), alternative therapies $144(72 \%)$, work activity $144(72 \%)$, environmental pollution $134(67 \%)$ social life $121(60.5 \%)$ and cigarette smoke $119(59.5 \%)$. The topics considered relevant was perceived to be able to influence disease symptoms. Regarding RD prevention, environmental pollution and cigarette smoking were considered the most important topics, while fewer patients believed that research on other topics could help to stop disease progression or to achieve disease healing.

\begin{tabular}{lccc}
\hline Ranking & Topic & $\begin{array}{c}\text { Not or quite } \\
\text { important }\end{array}$ & $\begin{array}{c}\text { Very or extremely } \\
\text { important }\end{array}$ \\
\hline 1 & $\begin{array}{c}\text { Doctor-patient relationship, } \mathrm{n}(\%) \\
\text { Psychological well-being/stress, } \mathrm{n}(\%)\end{array}$ & $12(6.0)$ & $188(94.0)$ \\
2 & Physical activity, $\mathrm{n}(\%)$ & $45(22.5)$ & $185(92.5)$ \\
3 & Nutrition/eating habits/alcohol, $\mathrm{n}(\%)$ & $50(25.0)$ & $155(77.5)$ \\
4 & Alternative therapies, $\mathrm{n}(\%)$ & $56(28.0)$ & $144(72.0)$ \\
5 & Work activity, $\mathrm{n}(\%)$ & $56(28.0)$ & $144(72.0)$ \\
6 & Environmental pollution, $\mathrm{n}(\%)$ & $66(33.0)$ & $134(67.0)$ \\
7 & Social life, $\mathrm{n}(\%)$ & $79(39.5)$ & $121(60.5)$ \\
8 & Cigarette smoke, $\mathrm{n}(\%)$ & $81(40.5)$ & $119(59.5)$ \\
9 & & &
\end{tabular}

Conclusion: This survey highlights the relevance of several unmet needs. The holistic approach, in terms of medical consultation and psychological well-being is considered the most important component able to influence disease perception. By capturing patient opinions on non-pharmacological topics for clinica research, this survey indicates that the active patient involvement is essential to design successful translational studies and improve clinical outcomes.

Acknowledgments: We thank the Lombard Association of Rheumatic Diseases (ALOMAR) for its contribution to plan and disseminate the survey and the group that sustain systemic sclerosis (GILS).

Disclosure of Interests: Francesca Ingegnoli: None declared, Tommaso Schioppo: None declared, Tania Ubiali: None declared, Silvia Ostuzzi: None declared, Massimiliano Buoli: None declared, Valentina Bollati: None declared, Roberto Caporali Consultant of: AbbVie; Gilead Sciences, Inc.; Lilly; Merck Sharp \& Dohme; Celgene; Bristol-Myers Squibb; Pfizer; UCB, Speakers bureau: Abbvie; Bristol-Myers Squibb; Celgene; Lilly; Gilead Sciences, Inc; MSD; Pfizer; Roche; UCB

DOI: 10.1136/annrheumdis-2020-eular.700

\section{AB1337-HPR PATIENTS' EXPERIENCE OF INVOLVEMENT IN A RHEUMATOLOGY OUTPATIENT CLINIC}

\section{P. Toftegaard ${ }^{1} .{ }^{1}$ Svendborg, Rheumatology, Svendborg, Denmark}

Background: Involvement in own treatment and care is a wish from patients and a vision from politicians in Denmark. $(1,2)$ In outpatient rheumatology patient involvement also leads to increased patient satisfaction, better quality of treatment and better utilization of resources in health care. $(3,4,5)$ On the basis of this we ought to involve our patients at our Outpatient Clinic in Svendborg, but are we?

Objectives: To gain knowledge about how patients with rheumatoid arthritis experience involvement in treatment and care in the Rheumatology Outpatien Clinic, Svendborg.

Methods: An interview study of six patients with subsequent analysis based on Ricoeur. (6) Patient inclusion: patients with rheumatoid arthritis in remission by DAS28 for more than 2 years. The participants elected were 3 males and 3 female at the age of $30-78$ visiting the clinic during Marts and April 2019. They were asked about their experience of involvement from time of diagnosis until present time.

Results: The study provided knowledge that patient involvement was new to the participants. This is also found in other literature about patient involvement. $(7,8)$ All participants in this study felt involved in own care and treatment. The involvement was based on being seen and heard as persons with individual needs and not just as patients with arthritis. The way the participants experienced involvement showed that there are individual differences in how to provide the experience. In order to clarify what involvement meant for each patient, relationship with the health professional was necessary, as other studies also shows. $(7,8)$ The relationship was conditioned by continuity, trust, care and mutual respect. For all the participants informed consent was equal to involvement. Disease activity or fear of this was the main reason for feeling involved this way. Literature describes the same: amongst other factors, the severity of the disease is significant for the patients desire to be involved. $(7,8)$

Conclusion: The participants experienced involvement in own care and treatment. The relation to the health professional was important providing this experience. All defined involvement as informed consent as it also is to many healthcare professionals. (9) All participants needed time to reflect on what 
involvement meant as none of them had heard of it before. Patient involvement needs education of both patients and healthcare professionals to be taken further than informed consent.

References:

[1] Ministeriet for Sundhed og Forebyggelse. Dialogpapir om øget inddragelse af patienter og pårørende: Ministeriet for Sundhed og Forebyggelse; 2014.

[2] Kompetencecenter for patientoplevelser. Den landsdækkende undersøgelse af patientoplevelser 2016. 2016

[3] Hewlett S, Mitchell K, Haynes J, Paine T, Korendowych E, Kirwan J. Patient-initiated hospital follow-up for rheumatoid arthritis. Rheumatology 2000;39(9):990-997.

[4] Schougaard LMV, Larsen LP, Jessen A, Sidenius P, Dorflinger L, de Thurah A, et al. AmbuFlex: tele-patient-reported outcomes (telePRO) as the basis for follow-up in chronic and malignant diseases. Quality of Life Research 2016;25(3):525-534.

[5] Hvidbog: national handlingsplan for leddegigt. S.I.: Vision Leddegigt 2020; 2016.

[6] Lindseth A, Norberg A. A phenomenological hermeneutical method for researching lived experience. Scand J Caring Sci 2004;18(2):145-153.

[7] Nota I, Drossaert CH, Taal E, van de Laar, Mart AFJ. Arthritis patients' motives for (not) wanting to be involved in medical decision-making and the factors that hinder or promote patient involvement. Clin Rheumatol 2016;35(5):1225-1235.

[8] Joseph-Williams N, Elwyn G, Edwards A. Knowledge is not power for patients: A systematic review and thematic synthesis of patient-reported barriers and facilitators to shared decision making. Patient Education and Counselling 2013:94(3):291-309.

[9] VIBIS. Læger og sygeplejerskers forståelse af patientinddragelse. 2014

Disclosure of Interests: None declared

DOI: 10.1136/annrheumdis-2020-eular.1835

\section{AB1338-HPR GLOBAL PATIENT PERSPECTIVE ON TOP CHALLENGES IN LUPUS CARE AND RESEARCH PARTICIPATION}

K. Tse ${ }^{1}$, Y. Peña ${ }^{2}$, K. Arntsen ${ }^{3}$, S. C. Bae ${ }^{4}$, L. Bloch ${ }^{5}$, I. N. Bruce ${ }^{6}$

K. Costenbader ${ }^{7}$, B. Dickerson ${ }^{8}$, T. Dörner ${ }^{9}$, K. Getz ${ }^{2}$, A. Kao ${ }^{10}$, S. Manzi ${ }^{11}$, E. F. Morand ${ }^{12}$, S. Raymond ${ }^{1}$, B. H. Rovin ${ }^{13}$, L. Schanberg ${ }^{14}$, V. Werth ${ }^{15}$, J. Von Feldt $^{16}$, D. Zook ${ }^{5}$, L. Hanrahan'. ' 'Lupus Foundation of America, Washington, DC, United States of America; ${ }^{2}$ Tufts Center for the Study of Drug Development, Boston, United States of America; ${ }^{3}$ Lupus and Allied Diseases Association, Verona, United States of America; ${ }^{4}$ Hanyang University Hospital for Rheumatic Diseases, Rheumatology, Seoul, Korea, Rep. of (South Korea); ${ }^{5}$ Faegre Drinker, Washington, DC, United States of America; ${ }^{6}$ University of Manchester, Division of Musculoskeletal and Dermatological Sciences, Manchester, United Kingdom; ${ }^{7}$ Brigham and Women's Hospital, Rheumatology, Inflammation and Immunity, Boston, United States of America; ${ }^{8}$ Aurinia Pharmaceuticals, Victoria, Canada; ${ }^{9}$ Charité University Hospital and DRFZ, Berlin, Germany; ${ }^{10} E M D$ Serono Research \& Development Institute, Inc. (a business of Merck KGaA, Darmstadt, Germany), Billerica, United States of America; ${ }^{11}$ Autoimmunity Institute, Allegheny Health Network, Pittsburgh, United States of America; ${ }^{12}$ Monash University, Medicine, School of Clinical Sciences at Monash Health, Melbourne, Australia; ${ }^{13}$ Ohio State University Medical Center, Columbus, United States of America; ${ }^{14}$ Duke University Medical Center, Durham, United States of America; ${ }^{15}$ Perelman School of Medicine at the University of Pennsylvania and CMCVAMC, Department of Dermatology, Philadelphia, United States of America; ${ }^{16}$ GlaxoSmithKline, Philadelphia, United States of America

Background: The Addressing Lupus Pillars for Health Advancement (ALPHA) Project is a global consensus initiative to identify, prioritize and address top barriers in lupus drug development, clinical care and access to care. The Lupus Foundation of America convenes ALPHA with Tufts Center for the Study of Drug Development and a Global Advisory Committee of lupus experts representing clinician-scientists, industry and patients.

Objectives: Collect global patient input to determine alignment with the lupus clinician-scientist community on prior published consensus of top lupus barriers. Methods: A 23-question online Qualtrics survey was developed to identify challenges across lupus diagnosis, clinical care and research participation. The survey, available in English, Spanish, Korean and simplified Chinese, was fielded in November 2019 to people with lupus and caregivers of children $<18$ with lupus. SPSS 26 and SAS 9.4 were used for descriptive statistics and sub-analysis.

Results: Analysis included only consented responses with $\geq 68 \%$ survey completion $(n=3,447)$ received across 83 countries. $95 \%$ were female with a mean age of 45 . Respondents reported being White (57\%), Black or of African descent $(14 \%)$, Hispanic or Latino (18\%) and Asian (10\%). $65 \%$ resided in the US while $35 \%$ resided in countries outside of the US. $97 \%$ were people with lupus while $3 \%$ were caregivers to children $<18$ with lupus.
Highest ranked challenges were similar globally and across children and adults: medication side effects, lack of treatment options and high out-of-pocket costs Managing side effects ranked significantly higher $(p<.05)$ outside of the US (48\%) compared to US (40\%). $50 \%$ of caregivers reported managing side effects as the top challenge for children compared to $43 \%$ of adults $(p<.05)$. Research participation was low (24\%) and lower among children (16\%). The top reason for not participating in a clinical trial was not being asked by their doctor.

Conclusion: This global survey revealed that medication side effects and lack of effective treatments are top challenges for people with lupus, including children. Most respondents were never asked by their doctors to participate in a clinica trial, which may explain difficulties in trial recruitment. These barriers are consistent with prior published barriers identified by the clinician-scientist community

Acknowledgments: ALPHA sponsors: EMD Serono, GSK, Aurinia, Mallinckrodt Disclosure of Interests: Karin Tse: None declared, Yaritza Peña: None declared, Kathleen Arntsen: None declared, Sang-Cheol Bae: None declared, Lauren Bloch Consultant of: Faegre Drinker Consulting is a division of Faegre Drinker Biddle \& Reath, a law and consulting firm that represents patient advocacy organizations and sponsors developing drugs, lan N. Bruce Grant/research support from: Genzyme Sanofi, GSK, and UCB, Consultant of: Eli Lilly, AstraZeneca, UCB, Iltoo, and Merck Serono, Speakers bureau: UCB, Karen Costenbader Grant/research support from: Merck, Consultant of: Astra-Zeneca, Bradley Dickerson Employee of: Aurinia, Thomas Dörner Grant/research support from: Janssen, Novartis, Roche, UCB, Consultant of: Abbvie, Celgene, Eli Lilly, Roche, Janssen, EMD, Speakers bureau: Eli Lilly, Roche, Samsung, Janssen, Kenneth Getz: None declared, Amy Kao Employee of: EMD Serono, Susan Manzi: None declared, Eric F. Morand Grant/research support from: AstraZeneca, Consultant of: AstraZeneca, Speakers bureau: AstraZeneca, Sandra Raymond: None declared, Brad H Rovin Grant/research support from: GSK, Consultant of: GSK, Laura Schanberg Grant/research support from: Sobi, BMS, Consultant of: Aurinia, UCB, Sanofi, Victoria Werth Grant/research support from: Biogen, Celgene, Gilead, Janssen, Viela, Consultant of: Biogen, Gilead, Janssen, Abbvie GSK, Resolve, AstraZeneca, Amgen, Eli Lilly, EMD Serono, BMS, Viela, Kyowa Kirin, Joan Von Feldt Shareholder of: GSK, Employee of: GSK, David Zook Consultant of: Faegre Drinker Consulting is a division of Faegre Drinker Biddle \& Reath, a law and consulting firm that represents patient advocacy organizations and sponsors developing drugs, Leslie Hanrahan: None declared DOI: 10.1136/annrheumdis-2020-eular.2871

\section{AB1339-HPR SAFETY AND ADHERENCE OF THE JAK INHIBITORS IN CLINICAL PRACTICE IN RHEUMATOID ARTHRITIS}

C. Valero $^{1}$, A. Calvo Garcia ${ }^{1}$, N. García Castañeda ${ }^{1}$, A. Ortiz ${ }^{1}$, I. Llorente ${ }^{1}$, B. Varas $^{2}$, S. Castañeda ${ }^{1}$, R. Garcia de Vicuna ${ }^{1}$, E. Ramirez ${ }^{1}$ on behalf of Rheumatology and Pharmacy Hospital De La PrincesaRheumatology Hospital Santa Cristina. ${ }^{1}$ Hospital De La Princesa, Madrid, Spain; ${ }^{2}$ Hospital Santa Cristina, Madrid, Spain

Background: The Janus Kinase (JAKi) inhibitors Baricitinib (BAR) and Tofacitinib (TOF) are indicated for moderate to severe active rheumatoid arthritis (RA). Data about safety, effectiveness in refractory patients and adherence in real clinical practice in our population are scarce.

Objectives: An evaluation of safety, adherence and reasons to consider suspension of JAKi in routine clinical practice.

Methods: Retrospective observational study of patients with RA treated with BAR and TOF according to usual clinical practice between September 2017 December 2019. Data were collected from the electronic medical record and from the Dominion® Outpatient Drug Dispensing program.

Demographic, clinical, laboratory and treatment-related variables were collected, including reasons for discontinuing JAKi (inefficiency and toxicity). Adherence was calculated using the Compliance Questionnaire on Rheumatology (CQR-5), and the average possession ratio (RMP), which is defined as the number of days with treatment dispensed between the total days of the period analyzed, considering the adherent patient when RMP had $a \geq 0.8$.

Laboratory abnormalities were defined according to normal limit values (NLV) and specifications of data sheet. A descriptive analysis was performed using proportions, medians and interquartile ranges (IQR) using the SPSS v.15 program. Results: Thirty patients were included in treatment with BAR and nine with TOF. The median age was 62.9 (RIQ 49.9-74.4), 34 (87.2\%) were women, 28 (71.2\%) anti-CCP and $32(82.1 \%)$ were rheumatoid factor positive, with erosive disease in $34(87,2 \%)$ patients. In the previous treatment, $9(23.1 \%)$ were naive to biological, $6(15.4 \%)$ had received 1 biological, 18 (46.1\%) 2 biologicals, and $6(15.4 \%)$ $\geq 3$ biologicals. The median treatment time was 8.4 months (RIQ 6.5-20.3) in BAR and 13.2 (RIQ 3.9-20.7) in TOF.

The reasons for consider suspension shown in Table 1. 